\title{
RECURSIONS
}

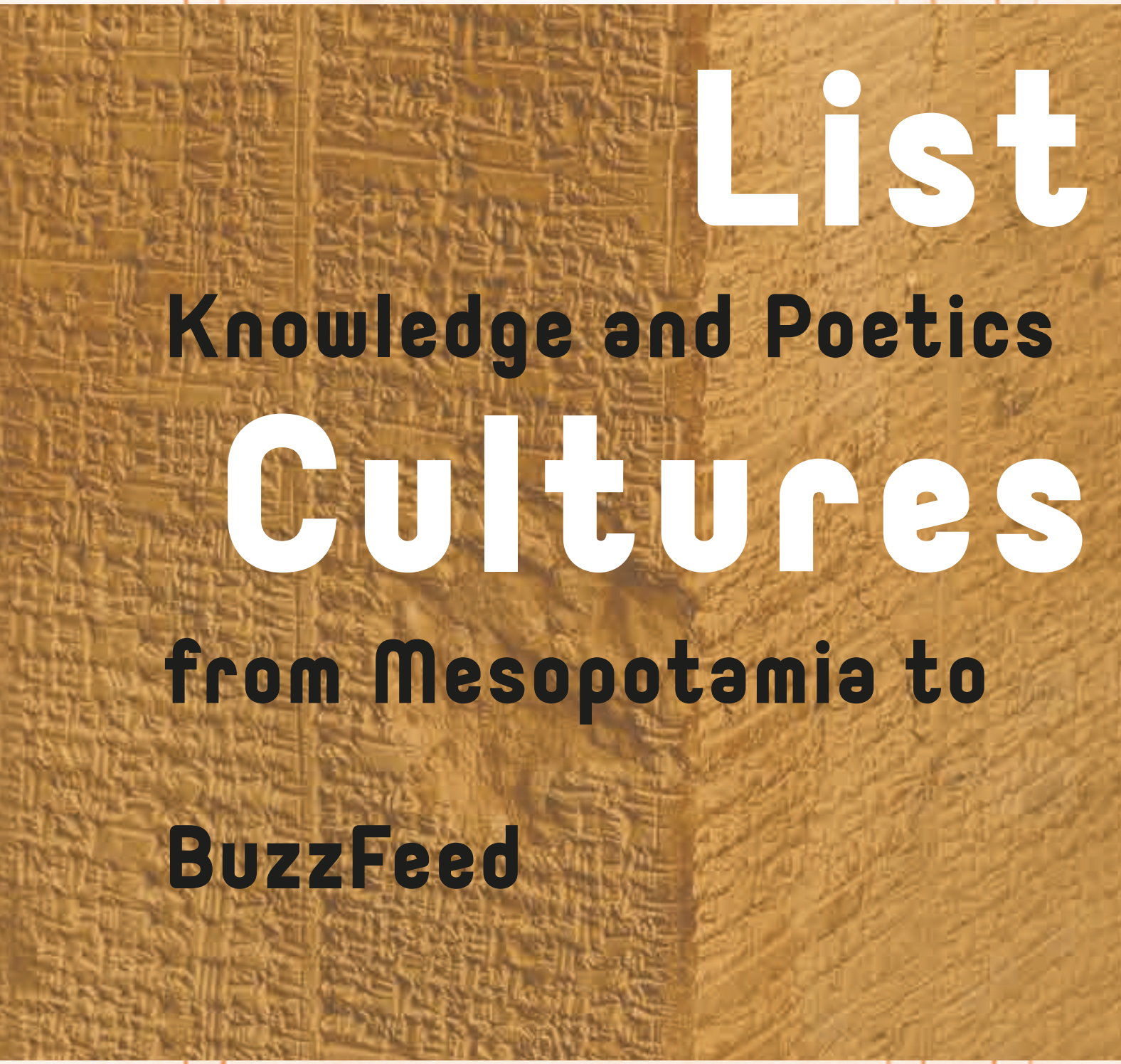


List Cultures 
The book series Recursions: Theories of Media, Materiality, And Cultural TECHNIQUes provides a platform for cuttingedge research in the field of media culture studies with a particular focus on the cultural impact of media technology and the materialities of communication. The series aims to be an internationally significant and exciting opening into emerging ideas in media theory ranging from media materialism and hardware-oriented studies to ecology, the posthuman, the study of cultural techniques, and recent contributions to media archaeology. The series revolves around key themes:

- The material underpinning of media theory

- New advances in media archaeology and media philosophy

- Studies in cultural techniques

These themes resonate with some of the most interesting debates in international media studies, where non-representational thought, the technicity of knowledge formations and new materialities expressed through biological and technological developments are changing the vocabularies of cultural theory. The series is also interested in the mediatic conditions of such theoretical ideas and developing them as media theory.

Editorial Board

- Jussi Parikka (University of Southampton)

- Anna Tuschling (Ruhr-Universitat Bochum)

- Geoffrey Winthrop-Young (University of British Columbia) 


\section{List Cultures}

Knowledge and Poetics from Mesopotamia to BuzzFeed

Liam Cole Young 


\section{Cover design: Suzan Beijer}

Lay-out: Crius Group, Hulshout

Amsterdam University Press English-language titles are distributed in the US and Canada by the University of Chicago Press.

$\begin{array}{ll}\text { ISBN } & 9789462981102 \\ \text { e-ISBN } & 9789048530670 \\ \text { DOI } & 10.5117 / 9789462981102 \\ \text { NUR } & 670\end{array}$

(c) L.C. Young / Amsterdam University Press B.V., Amsterdam 2017

All rights reserved. Without limiting the rights under copyright reserved above, no part of this book may be reproduced, stored in or introduced into a retrieval system, or transmitted, in any form or by any means (electronic, mechanical, photocopying, recording or otherwise) without the written permission of both the copyright owner and the author of the book.

Every effort has been made to obtain permission to use all copyrighted illustrations reproduced in this book. Nonetheless, whosoever believes to have rights to this material is advised to contact the publisher. 


\section{Table of Contents}

$\begin{array}{ll}\text { Acknowledgements } & 7\end{array}$

$\begin{array}{ll}\text { Preface } & 9\end{array}$

Introduction 11

1. History: Lists and Media Materialism 23

2. Epistemology: Pop Music Charts and the Making of a

$\begin{array}{ll}\text { Cultural Field } & 45\end{array}$

3. Administration I: The State, the Fact, and Double-Entry

$\begin{array}{ll}\text { Bookkeeping } & 67\end{array}$

4. Administration II: The Nazi Census and Making Up People 85

5. Logistics: Listicles, Algorithms, and Real Time 109

6. Poetics: Uncanny Modernity in Heidegger, Borges, and Marker 131

$\begin{array}{ll}\text { Conclusion: Etcetera... } & 153\end{array}$

$\begin{array}{ll}\text { Notes } & 157\end{array}$

$\begin{array}{lr}\text { Bibliography } & 179\end{array}$

$\begin{array}{ll}\text { Index } & 191\end{array}$ 


\section{Acknowledgements}

A first book is a strange thing. It emerges from an intense solitude that, if one is lucky, is sandwiched by periods rich with dialogue, collaboration, and conviviality. I am grateful to have been so lucky.

Thanks are due, first and foremost, to the many readers of the many drafts of this project: to Bernd Frohmann, for his limitless hospitality and friendship, his extraordinary dedication as a reader, and his precise and unflinching editorial eye; to John Durham Peters, whose unique talent for making the familiar strange pushed this project where it needed to go; to Nick Dyer-Witheford, for provocations both intellectual and political; to the 'Recursions' series editors, Jussi Parikka, Anna Tuschling, and Geoffrey Winthrop-Young, for their support and careful stewardship; to Grant Campbell, Alison Hearn, Chris Keep, Susan Knabe, and Tony Purdy, for their insightful and incisive comments; to Kenneth C. Werbin, for his pioneering work on listing and security; and to the editors and anonymous peer reviewers at Canadian Journal of Communication, Theory, Culture, and Society and Amodern, where early sketches of this project appeared in 2013.

I am grateful for the friendship of Warren Steele, whose brave and brilliant answers to the impossible question of 'the meaning of technology' have shaped this research in ways too numerous to count. My thanks, also, to Chad Andrews, Michael Daubs, Atle Mikkola Kjøsen, Danielle Taschereau Mamers, Vincent Manzerolle, Henry Adam Svec, and Elise Thorburn for their friendship and formidable intellectual talents. Conversations and correspondence with this group were decisive in developing this book.

I have been lucky to develop as a thinker, writer, and teacher in spaces of robust but collegial intellectual debate; thanks to my friends, colleagues, and teachers at Western, Trent, Brock, and Carleton Universities for inspiring and sometimes infuriating me. I would also like to acknowledge the students I've had the pleasure of teaching over the years, whose enthusiasm and patience enabled me to test out many of the ideas contained in these pages. I am additionally grateful for the generous support of the Ontario Ministry of Training, Colleges, and Universities, and the Social Science and Humanities Research Council of Canada.

A book on lists wouldn't be complete without plunking down a heap of names, so I thank, for their company, ideas, and provocations, Luke Arnott, Jonathan Bordo, Zak Bronson, Lilianne Dang, Michael Epp, John Fekete, Scott Henderson, Hugh Hodges, Svitlana Matviyenko, Dilyana Mincheva, Liam Mitchell, Michael Morse, Bohdan Nebesio, Davide Panagia, Chris 
Russill, Will Straw, Tiara Sukhan, Ira Wagman, and Darren Wershler. Thanks also to organizers and audiences at conferences and symposia including 'Network Archaeology' (Miami OH University, 2012), the Centre for the Study of Theory and Criticism's Theory Sessions (Western University), Trent University's 2016 MA in Public Texts colloquium, as well as the annual meetings of the Canadian Communication Association, the Document Academy, the International Association for the Study of Popular Music, and the Popular Culture Association of Canada.

Heartfelt thanks to my family-brother Matt, sister-in-law Jolene and their three precocious children, 'Sloane, Jone, and Bone'; sister Erin, brother-in-law Roger, and their gang of four, Kennedy, Grace, Matteo, and Isla; step-sister Catherine, sister-in-law Sarah and her partner Jona; and of course my parents, new and old: Lorette and Peter Bentley, Jim and Kim Young, Marilyn and Lorne Brack. Their collective support of this project and love of its author have known no bounds.

Last but not least: thanks to Katie, my partner and my buddy, who tops the list in every category. These pages testify to your belief and love, and to the warmth, honesty, and grace with which you greet each day. 


\section{Preface}

'We like lists because we do not want to die,' quipped the late, great Umberto Eco. The occasion for this remark was the opening of his 2009 Louvre exhibition, 'The Infinity of Lists', a dizzying exploration of listing activities over the last 5000 years. Curating the exhibition compelled the Italian polymath - who knew more than a little about such matters- to claim the list as 'the origin of culture."

Eco was not the only literary figure with a fondness for the humble list form. 'Bare lists of words are found suggestive to the imaginative and excited mind,' wrote Ralph Waldo Emerson, whose work is littered with enumerations. ${ }^{2}$ We also learned, upon her passing, of cultural critic Susan Sontag's self-described list 'compulsion'. ${ }^{3}$ Curators of the born-digital Sontag archive at UCLA were baffled by the preponderance of lists on her hard drives: topics she planned (or hoped) to write about; listed records of correspondence (incoming and outgoing: who wrote what and when and to whom); pages of titles of films and images (viewing reminders? a canon of her favourite pieces? things to keep in mind?) and, of course, to-do lists, those gentle giants of administration that do so much heavy lifting for us, but whose burdens weigh us down.

Sontag's beguiling lists illustrate everything that this book is about. They show how a study of lists is a battle against entropy. When you start looking for lists, they are every where; when you start talking about lists, your eyes and ears are filled with suggestions and ideas. One's only recourse is to add these to a list of things to consult, to read, to think about. Sontag's archive shows that lists categorize, yet, at the same time, defy categorization. This is perhaps their essential feature. We typically think of lists as administrative: they organize thoughts, offer reminders (not always friendly), and help get things done. But they do so much more than this. Lists draw things together and allow us to forge connections between divergent items, placing them under a logic that is all our own. This seemed to be what so fascinated Sontag about the form. By making lists, she wrote, 'I perceive value, I confer value, I create value, I even create-or guarantee-existence. ${ }^{4}$ This is strong language from someone not prone to exaggeration.

Found lists, like those on Sontag's hard drives, are ruins. Like found photographs, they are tinged with melancholy and longing. They seem to swirl around death, poignantly marking absence or loss. We come across another person's shopping list only after it has been cast aside, having served its purpose or been abandoned mid-stream. What is a to-do list 
when it can no longer remind, organize, or program action? Having lost its ability to do, and absent of any doer, it is a trace of past action, a vestige of possibility never realized. Who was this person? What happened to make them abandon this list? Even when we know its author, a list draws us in. Sontag's are mysterious because they slice through traditional modes of classification and lack context or description. What did they mean to her? What was their purpose or function? How did she think about them? How did they affect her thinking? Such lists seem to speak from the void, provoking thought, grief, and wonder.

The list is a form that mediates boundaries between administration and art, knowledge and poetics, sense and nonsense. It operates in the realm of ontics, a realm that recent 'German' media theory presents as prior to, and thus constitutive of, such aspects of human culture and society as knowledge systems, rituals and traditions, forms of selfhood, even modes of being. ${ }^{5}$ The archaeological record is filled with examples of human societies using lists to hold themselves together across space and time, from literary lists like Homer's catalogue of ships to complex algorithmic writing in computation, and the billions of inventories and to-do lists in between. Such listing activities are the infrastructure of culture, making lists an ideal object for media theory. They help us glimpse the techniques and technologies by which human societies administer, police, and imagine themselves. In so doing, lists invite us to return with fresh eyes to a 'civilizational' approach to media history developed in Canada during the middle decades of the twentieth century, and most closely associated with Harold A. Innis and Marshall McLuhan.

Listing - as Sontag, Emerson, Eco, and Homer understood — is immensely powerful. But what is the nature of this power? Where and how does it operate? From where comes our impulse to list? Is there something about this form that speaks to our current historical moment? In what ways have other cultures used lists? How can we even begin to ask these questions? At the onset of this project, I was not sure. So, taking inspiration from Walter Benjamin (who is always good for inspiration), I started collecting, observing, and speculating, with no destination in mind. This took me to many surprising places: from the Top-40 charts in pop music that spurred my initial interest to grain inventories of Ancient Sumerians; from the florilegia of mediaeval manuscript culture to modern bureaucracies; from Melville's cetological classifications to BuzzFeed listicles; from computer programming to Borges' infinite libraries. The list tells many stories. Some appear in these pages. Most remain as fragments in notebooks, lists to be rediscovered somewhere down the line. 


\section{Introduction $^{1}$}

'An inclusive list of media effects opens many unexpected avenues of awareness and investigation' - Marshall McLuhan ${ }^{2}$

Start with five lists from recent headlines (in no particular order):

March 2014 - the governments of the United States and Russia engage in a tête-à-tête over Crimea that revolves, largely, around lists. An executive order from US President Barack Obama 'black lists' eleven officials of the Russian government as well as 'any individual or entity that operates in the Russian arms industry, and any designated individual or entity that acts on behalf of, or that provides material or other support to, any senior Russian government official. ${ }^{3}$ In response, Russia releases a list of Americans no longer welcome for business, diplomatic, or leisure purposes. Neither list proves effective in addressing the immediate issue of Russia's annexation of Crimea, but both are economical nuggets of information easily digested by the 24-hour news cycle.

April 2014-changes to the Canadian Navigable Waters Protection Act (NWPA), proposed by Stephen Harper's Conservative government in its 2012 omnibus budget bill C-45, take effect. The NWPA — an Act in which the default status for Canadian waterways was environmental protection under common law ${ }^{4}$ - becomes the Navigation Protection Act. Waterway protection is reconfigured under the new act around economic interests and enforced by a new 'List of Scheduled Waters'. This list denies protection to 99.7 per cent of Canada's lakes and 99.9 per cent of its rivers. Notable exclusions are the Kitimat and Upper Fraser Rivers, which lay along the path of the proposed Northern Gateway Pipeline. Notable inclusions for protection are cottage country lakes in British Columbia and Ontario, where 'powerboat owners will maintain unfettered navigation protections.'5 Protection is now exception; exception is granted by the 'List of Scheduled Waters'.

November 2015-While campaigning for the 2016 Republican Presidential nomination, Donald Trump replies 'Oh, I would certainly implement that-absolutely,' when asked if the United States should create a database of Muslims in the country. He adds that he would employ 'good management procedures' to get Muslims entered into the database. ${ }^{6}$ 
October 2015 - The Intercept goes public with its latest bombshell intelligence leak, 'The Drone Papers'. A whistleblower 'from inside the intelligence community who worked on the types of operations and programs described' suggests he was compelled to act after learning of kill-listing activities of the American government. 'This outrageous explosion of watchlisting —of monitoring people and racking and stacking them on lists, assigning them numbers, assigning them "baseball cards", assigning them death sentences without notice, on a worldwide battlefield—it was, from the very first instance, wrong. ${ }^{7}$

October 2014-author Shaun Usher releases Lists of Note, a book that, he says, speaks to the 'depth of [hu]mankind's obsession with lists. ${ }^{8}$ The book contains poetic and quotidian lists from historical figures both prominent and obscure. Some notable inclusions: Galileo's 1609 shopping list; Albert Einstein's list of conditions for prolonging his marriage to Mileva Maric (1914); a list of objections given to Charles Darwin by his father about a proposed journey aboard the HMS Beagle (1831); and Johnny Cash's whimsical to-do list, most likely a love letter sent to June Carter-Cash.

These examples show how lists and rankings proliferate at every turn: online and offline, at work and at play, in politics and art, in 'high' culture and 'low' culture, in conversation and print. Shopping lists, bucket lists, no-fly lists; as Werbin writes, 'in lists we are.' ${ }^{9}$

Our relationship to the form is complicated. Though they shoulder heavy administrative and organizational burdens, we heap scorn on the use of lists in cultural or literary contexts: arguments about listicles degrading long-form writing, or bullet points leading to limited attention spans, are as ubiquitous as the lists themselves. We are told that 'best of all time' collections strip meaning and context from great works of art. Many a critical theorist has argued that list-like forms debase reason. ${ }^{10}$ In spite of these reservations, we list on. Countdowns, rankings, and 'best of the all-time' collections are ubiquitous. The list seems almost paradigmatic of digital culture: the zeitgeist in a BuzzFeed listicle.

Why this explosion of lists, and why now? One's first instinct is to suggest it has something to do with huge increases in the volume and velocity of data flows - lists as a strategy of managing 'information overload'. ${ }^{11}$ Certainly, both producers and consumers have turned to the form, producers to quickly communicate information, consumers to help navigate a perceived information deluge. Lists reduce noise in the channel (the most important condition for any successful communicative act according to Claude Shannon's famous 'Mathematical Theory of Communication'). ${ }^{12}$ There are political stakes to this information ecology. Political discourse and action 


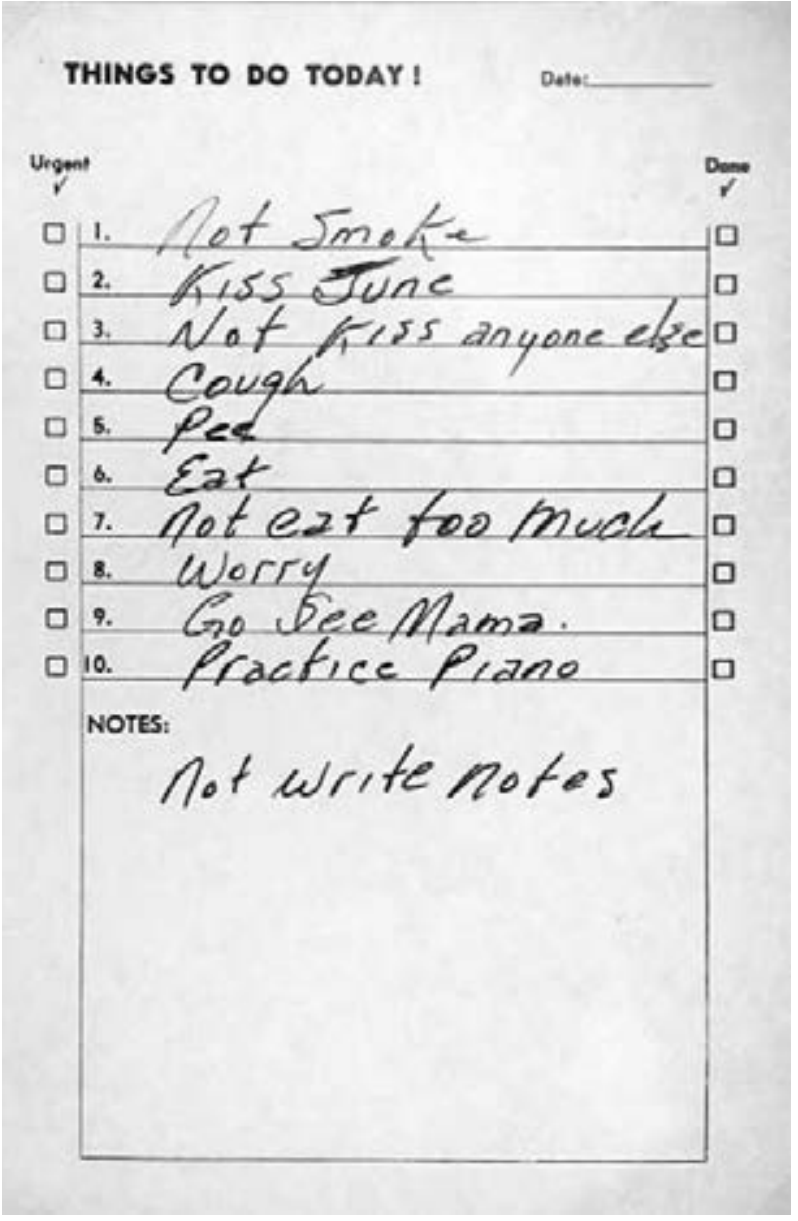

Johnny Cash's to-do list, (date unknown).

are shaped by the communicative forms and processes available to citizens. In networked society, as Terranova and others show, the complexity of the world is broken down into a series of resolvable probabilities (yes/no, good/ bad, us/them, important/unimportant, etc.). ${ }^{13}$ These are contained in and delivered by communicative forms like lists. In this light, the list appears as an agent by which identities, institutions, economies, and governments are policed via neoliberal techniques of measure, enumeration, and data analytics.

But is the story so simple? Information overload is not unique to digital culture. We have been complaining that there is 'too much to know' since at least the early modern period (more probably since antiquity). ${ }^{14}$ 'There are so 
many books that we lack even the time to read the titles,' bio-bibliographer Anton Francesco Doni noted in $155^{0 .}{ }^{15}$ Nor is the administration of bodies by lists new, as the horrors of the Holocaust and the French Terror remind us. And furthermore, progressive political movements use lists, too. Friedrich Engels's The Conditions of the Working Class in England was based on his 1842-1844 surveys of the poor of Manchester: disease and mortality rates, population growth and density, import/export figures, number of mines, etc. $^{16}$

Though it feels new, listing is an ancient cultural technique. The earliest surviving examples of writing are administrative lists inscribed on clay tablets by ancient Sumerians. These were both administrative (facilitating trade and other economic activity), and mnemonic (storing useful information about transactions and inventories). Such lists arose as a result of the needs of public economy and administration. ${ }^{17}$ More sophisticated uses for lists cropped up as societies of antiquity began to collect large numbers of texts in libraries such as Alexandria. Reference tools emerged that 'built on preexisting practices of list making (including Aristotle's pinakes of poets), sorting (such as Theophrastus's doxographies sorted topically and chronologically), and alphabetizing. ${ }^{18}$ Later came the florilegia of medieval scholars - a note-taking technique that involved compiling notable excerpts from other texts - as a direct response to the early modern lament, traced by Anne Blair, that there was 'too much to know.' In 1548, Konrad Gessner describes a technique of cutting up pieces of information on paper so as to re-arrange them, probably the earliest account of an efficient technique of generating many alphabetized lists. ${ }^{19}$

Listing as a technique and the list as a form show up in every bureaucratic apparatus conjured by modern minds and hands to address the needs of emergent institutions like the state and the corporation, and it haunts the work of every great thinker of bureaucracy and administration from Weber to Latour. Lists today are ubiquitous not only at the interface level of web aesthetics, but also in giving form to protocols and algorithms. In short, lists have been a part of every new media ecology and its corresponding 'flood' of information - from ancient administrative writing through early modern manuscript and modern print culture, to the analogue world of gramophone, film, typewriter, and into the digital code of network society. Clearly, preliminary hypotheses that regard it as either a corollary of network society's 'information overload', or as a surreptitious agent of neoliberalism, are not sophisticated enough to do justice to a form that exists in, or alongside, almost every inscription system on record. 
How to explain this persistence? What can its varying historical functions teach us about the list's ability to survive shifts in ways of knowing? By collecting and materializing information, do lists create fields of knowledge? How do they structure the way data and knowledge circulate? What are the ethics of listing, a technique that has been complicit in the administration of human populations and in the 'disenchantment' of the modern world? Does list-making offer opportunities for challenging dominant systems of classification or ways of knowing? What is the role of the list in digital media environments, and in human artistic expression? Such questions guided my research, and this book exists because cultural and media studies do not yet have adequate tools to answer them.

Lists are important to media theory because they link familiar techniques of data organization and control with those that are much older. Lists offer a heuristic that allows us to see connections between digital media and the origins of writing. That they have received relatively little scholarly attention is surprising - an aporia perhaps indicative of a general trend in media studies to conflate layers of form, content, technique, practice, and habit under totalizing categories like 'media' or 'network'. Because they travel amongst and through media objects and networks, lists teach us about the way data become culturally inscribed as knowledge. Yet, lists are unique in their ability to interrupt the same systems of knowledge production and circulation that they seem, on the surface, only to enforce. This is a key point, and the crux of my argument: lists teach us about the systems of order that surround and enframe us because they simultaneously conceal and reveal, enforce and subvert the contours of such systems. Lists inscribe ways of seeing and knowing the world that they elsewhere make strange. Nobody understood this better than Borges, whose playful and beguiling creations teach us more about the classification and circulation of knowledge than thousands of pages of philosophy. From 'The Analytical Language of John Wilkins':

These ambiguities, redundancies and deficiencies remind us of those which doctor Franz Kuhn attributes to a certain Chinese encyclopaedia entitled 'Celestial Empire of benevolent Knowledge'. In its remote pages it is written that the animals are divided into: (a) belonging to the emperor, (b) embalmed, (c) tame, (d) sucking pigs, (e) sirens, (f) fabulous, (g) stray dogs, (h) included in the present classification, (i) frenzied, (j) innumerable, $(\mathrm{k})$ drawn with a very fine camelhair brush, $(\mathrm{l})$ et cetera, $(\mathrm{m})$ having just broken the water pitcher, (n) that from a long way offlook like flies. ${ }^{20}$ 
We will return to Borges and his taxonomy in the latter stages of this book. For now, I set him aside in order to address one question in particular that looms over this project: what, precisely, is a list?

\section{'What is a list?' or, are we asking the right question?}

The list is hard to pin down. It can function variously as a communicative device, a cultural form, an operational mode of writing, a storage or archival device, a poetic form, and a mediator. Lists can be past, present, or future oriented; retroactive, administrative, or prescriptive. Lists are sometimes registers that index, and at other times metrics that rank and compare. Belknap's is a useful preliminary definition: 'At their most simple, lists are frameworks that hold separate and disparate items together. Lists are plastic, flexible structures in which an array of constituent units coheres through specific relations generated by specific forces of attraction. ${ }^{\prime 21}$ But so are sentences and paintings. Belknap's definition, if we are trying to pin down what exactly a list is, seems hopelessly open-ended, including everything from taxonomies, recipes, rankings, inventories, catalogues, lexicons, etc. He addresses this problem by distinguishing between pragmatic and literary lists. The former are quotidian lists of the everyday, enumerative containers that are concerned with the storage and retrieval of information and so do not mean anything, at least in literary terms. Literary lists, on the other hand, 'appeal for different reasons. [In them] we do not hunt for a specific piece of information but rather receive the information the writer wishes to communicate to us. ${ }^{22}$

This distinction allows Belknap to offer a convincing case for what literary lists are and what they mean. But in limiting his focus to the literary he turns away from the majority of lists we encounter every day. How can we also account for lists in administration, a realm where they have dwelled for thousands of years? Furthermore, are literary and pragmatic lists so different? Another of Belknap's strategies can help with such questions. Just as he looks first at what lists $d o$ in literature before speculating about what they are or mean, so too must we look at what pragmatic lists do. Starting with an essential definition of what a list is or means-or even using these as animating questions - shuts down the generative potential of analysis. It locks the researcher into a trajectory that, in its quest for scientific accuracy, leads only towards negation - the list is not that, or the list is only this and never that. I propose a more generative approach that starts not with the question of what a list is or means, but rather asks 
what lists do: administratively, communicatively, epistemologically, even poetically. ${ }^{23}$

Media materialism offers tools required to pursue a functional history or genealogy of listing activities. With 'media materialism', I seek to capture

a loose grouping of media-theoretical concepts and approaches including (but not limited to) media archaeology, theories of Kulturtechniken ('cultural techniques'), critical infrastructure and logistical media studies, as well as their historical antecedents in the 'civilizational' stream of media history pioneered by Harold A. Innis and Marshall McLuhan at the University of Toronto, c. 1930-1970. At a micro level, this grouping is interested in objects and texts not in terms of interpretation, meaning, or content, but rather in terms of the physical properties of surfaces and the techniques of inscription, transmission, and reception that structure them. At a macro level, media materialism is interested in the historically specific arrangements of spatial and temporal factors related to knowledge systems and information flows - what Innis first understood with the concepts of space- and time-bias. ${ }^{24}$ I expand on this intellectual lineage, and my contribution to it, in Chapter one. For now, I will note that media materialism fills gaps in the currently dominant paradigms of what is called 'media studies' in Anglo-America. These are, generally, cultural studies approaches that emphasize textuality, subjectivity, and reception, on the one hand, and political economic approaches that emphasize systemic and institutional factors, on the other. This binary is crudely drawn but heuristic. It provides a useful orientation to an ongoing conversation into which List Cultures intervenes.

\section{The arguments}

This book develops four intersecting arguments. The first is disciplinary and methodological. It contributes to calls for contemporary media and cultural studies to more forcefully integrate media materialist approaches and concepts. Such approaches allow us to develop more accurate accounts of media networks and environments (contemporary and historical) than those that focus on use or ownership. Media materialism takes into account more than devices, institutions, texts, and audiences. It 'un-black boxes' the usual objects of media studies to illuminate forms, formats, techniques, protocols, programs, etc. that play crucial roles in the establishment and functioning of media-technological systems, but which are too often conflated under broad concepts like 'media' and 'network'. My contribution is to 
bring forward the 'civilizational' stream of media materialism, particularly its Canadian iteration, which brings much to current debates.

The second argument presents the list as a concrete example of what media materialism brings into view. Listing is a cultural technique that performs ontic operations that inscribe concepts and categories upon which technical systems and social institutions are built. As a form that is constitutive of certain kinds of knowledge, the list can tell us much about the material circumstances in which human beings enact thought and action.

The third and fourth arguments are about lists themselves. Argument (3) is that lists cannot be easily dismissed or endorsed. It is not enough to say lists are good or bad. Their complicated and sometimes contradictory operations-observed throughout this book-demand a precise tracing of how they function. Argument (4) proposes that the enduring presence of the list in our thoughts, texts, and programs arises from its unique capacity to negotiate tensions and paradoxes that have perplexed us for millennia. These include fear and desire, wonder and horror, entropy and order. The latter tension, which Eco describes as a poetics of 'etcetera' vs. 'everything-included', is particularly important to this project. ${ }^{25}$ I will show that, on the one hand, the list's tendency towards 'everything included' (i.e. the drawing of borders) has led it to be harnessed by forces of rationality and governmentality that categorize and administer people, words, and things. On the other hand, the list has the capacity to negate such forces and open spaces for thinking beyond their limits. The poetics of etcetera can challenge the logic of everything-included; the paradigmatic AND, AND, AND of the infinite can displace the syntagmatic IF/THEN of the finite. This double function resonates with Jack Goody's dialectic understanding of lists, discussed in Chapter one (that they challenge the boundaries of knowledge that their borders materialize) and with Martin Heidegger's understanding of the relationship between art and technology, wherein the 'saving power' exists precisely where the 'danger' is most imminent (discussed in Chapter six).

These four arguments run parallel and often intersect. Studying the list does not offer us a convenient, Malcom Gladwell-esque insight into the nature of humanity forever and ever amen. Lists are not deterministic but heuristic. Through them we can map and compare shifts in ways of knowing. Tracing their operations gives us fresh insight into how we think, how we do, and how we imagine. They show us, if we know how to look, the ways that our rules and desires are encoded in various techniques of knowledge production and circulation, administration, and poetry. 


\section{Method and chapters}

Because lists are ubiquitous and innocuous, it is difficult to bring them into focus. They are so woven into the fabric of our media and information environments that we do not often notice their presence. The list is part of what McLuhan called the 'ground'; the challenge here is to make it a 'figure'. One way to do this is to trace and compare list operations in a number of social, historical, and technical contexts. Rather than one argument about lists repeated over similar case studies (i.e. variations on a single theme), I have chosen to weave each of the four arguments above through case studies from different realms: epistemology, administration, logistics and computation, and poetics.

The arguments and case studies do not simply map onto one another. The popular music charts of Chapter two do not only teach us about cultural knowledge and history, nor do the computational lists of Chapter five teach us only about real time. Some tendencies are more evident in certain contexts than in others. Such differences emphasize that the list cannot be reduced to any single thing. I thus intentionally avoid judgement-lists as either good or bad, this or that, here or there - moving analysis beyond stock ideological critique. Such an approach, and the binary categories it relies upon, is not helpful in thinking about a form that has been in constant use for 5000 years. Of course there are ideological dimensions to lists—such an adaptable form of organizing and communicating information can and has been mobilized for various ends. But this kind of critique places too much emphasis on the content of lists at the expense of their operations. Latour's first rule of method is a good rule of thumb: instead of black-boxing the technical or material aspects of the list and then looking for social influences and biases, I seek to 'be there before the box closes and becomes black., ${ }^{26}$

The list as an object attracts various methodological approaches. In addition to Latour, I borrow from the structural and institutional critique of communication studies and critical theory; the emphasis on inscription surfaces and techniques from media theory and documentation studies; and the close reading of literature and film studies. That these approaches can be productively combined speaks not only to how lists draw things together, but to the fact that, on their own, such traditional approaches are unable to account for the 'hidden' layer of list-like forms that travel through media networks, texts, and institutions, and which have many often-competing functions. 
This research is equal parts synthetic, primary, and interpretive. It brings fresh eyes to familiar forms and proceeds as follows: Chapter one traces a brief history of 'list' as a concept, intellectual technology, cultural practice, and object of study. I expand on the challenges it poses to traditional interpretive approaches in media and cultural studies and sketch, with more specificity, approaches and concepts from media materialism that I find better suited for analysing lists and listing. I also foreground the modest contribution of List Cultures to this intellectual lineage.

Chapters two, three, and four re-read familiar histories through the lens of media materialism, following the list into seemingly disparate fields and historical moments. Chapter two builds on Bruno Latour's early science studies work to trace the list as a standardized format that structures the production, circulation, and reception of knowledge in popular music. It asks: what does the history of popular music look like if we view charts not as a political economic phenomenon, nor as a vector for exploring consumer subjectivity and identity, but as a cultural technique of categorization that structures the epistemology of a cultural field? I show how lists were present in this field from the beginning, and how institutionally-sanctioned lists, e.g. the 'charts', continue to inscribe borders and draw distinctions that enact categorizations and modes of classification. Popular music is a field where lists are particularly easy to trace, and where they receive a relatively unusual amount of critical attention. We can learn from this attention and export it to other realms where lists are no less present but much harder to observe.

Chapters three and four shift focus from the role of lists in making knowledge to their role in what Hacking calls 'making up people'. ${ }^{27} \mathrm{We}$ move from lists of words and things to those of number and human beings. Chapter three traces the list form in the emergence of fifteenth-century Italian double entry bookkeeping. Building on Mary Poovey's argument that double entry bookkeeping established a concept of 'fact' upon which modern empirical structures of knowledge were built, in Chapter four I connect this way of looking at words, things, and number to Nazi administration (which I describe metonymically as 'the Nazi census'). Luca Paciolli's series of interconnected lists established new categories of economy in the same way that Nazi registers inscribed new categories of personhood. Chapter four asks: what do we learn by reading Nazism as a modern phenomenon not at a philosophical level, as done most famously by Horkheimer and Adorno, but by looking at cultural techniques of paperwork? In doing so, we grasp how such techniques structure a particular way of understanding the world that is about logistics: the movement of people, things, and data through time and space. This 'logistical orientation' frames the earth and 
its inhabitants as material to be ordered according to human ends, what Heidegger referred to as Bestand ('standing-reserve'). Nazi listing techniques are a limit case study, included not to shock the reader or bring gravitas to this research, but again because its list operations are relatively easy to trace. There is a plethora of archival material and research on the subject. The familiarity of the historical event also shows us the power of re-reading history through the lens of media materialism.

Chapter five moves to the contemporary world, learning from the historical excursions of earlier chapters to explore how lists of code and protocol in computation are infrastructural elements of 'logistical modernity' (a term Benjamin Bratton uses in describing Paul Virilio).$^{28}$ Computational lists are elegant data structures that operate in real time to facilitate what is required of them: compression, calculation, and circulation. In this way, they can be connected to earlier case studies. Real-time operations of logistical lists make them a privileged operator at both code and interface level. Big databases are lists, as are algorithms, and their logic finds expression in datamining techniques used in state surveillance and corporate-commercial sectors alike. A 'new media' corporation like BuzzFeed is a paradigmatic example of how list-protocols structure computational processes, interface aesthetics (e.g. listicles), and corporate organizations. Surprisingly, the timecritical dimension of logistical lists brings forth a connection to ancient, non-narrative modes of relaying the past. Real-time operations channel the chronicle and the epic, what Ernst calls modes of 'counting' rather than 'recounting'. ${ }^{29}$ This moves lists beyond logistics and administration into the realm of poetry.

Chapter six picks up this suggestive thread, offering a more redemptive reading of listing. Using the words of Borges and Benjamin, and the images of Chris Marker, I show the list as an imaginative form that can explode the structures of order it elsewhere enforces. Such lists offer a unique space for what Heidegger understood with the concept poiesis. Lists here render the structures and limitations of modern thought uncanny, they intrude on modern historical and narrative time by channelling other, non-narrative times and affects, thereby preserving a heterotopian space for thinking 'other'.

I draw together this collection of divergent and seemingly arbitrary case studies to show how lists materialize connections, previously invisible, between realms, worlds, and historical moments, making visible a world of secret affinities. 'To write history [...] means to quote history, ${ }^{\prime 30}$ wrote Benjamin, lover of list and aphorism. Through quotation and enumeration, we interrupt the continuum of History, and it is in the spirit of Benjamin's 
listed scraps of observations, analysis, and quotation that the following is offered. Let us now explore some of the functions and poetics of a form that has resonated for over 5000 years in our programs and our imaginations, which are usually not so different. 